Volume 2, Nomor 1, Tahun 2020 Hal 312 - 320

\title{
Penyuluhan Pentingnya Pendaftaran Tanah Desa Binaan Kecamatan Pematang Sidamanik, Kabupaten Simalungan Aartje Tehupeiory ${ }^{1}$, I Dewa Ayu Widiyani ${ }^{2}$, Gindo L Tobing ${ }^{3}$, Diana Napitupulu ${ }^{4}$
}

\author{
1,2,3,4, Universitas Kristen Indonesia, Jakarta, Indonesia
}

e-mail: ${ }^{1}$ aartje.tehupeiory@uki.ac.id, ${ }^{2}$ ayu.widyani@uki.ac.id, ${ }^{3}$ gindo.tobing@uki.ac.id,

${ }^{4}$ diana.napitupulu@uki.ac.id,

\begin{abstract}
Abstrak
Pentingnya Pendaftaran Tanah dilaksanankan di Desa Binaan Kecamatan Pematang Siantar, Kabupaten Simalungan selama 2 hari yakni tanggal 14, 15 agustus 2019. Dilaksanakan dalam bentuk penyuluhan Hukum di bidang Hukum Pertanahan, bertujuan untuk memberikan pengetahuan dan kesadaran pada masayarakat pentingnya pendafatran tanah bagi masyarakat untuk mendapatkan kepastian hukum bagi tanahnya yang dimiliki sehingga menimbulkan rasa mantap dan rasa aman bagi masyarakat yang memiliki tanah yang dihaki. Selanjutnya ada perlindungan hukum untuk untuk mencengah gangguan dan penguasaan sesama warga masyarakat. Dengan alat bukti yang dihasilkan pada akhir proses pendaftaran tanah berupa buku tanah dan sertifikat tanah yang terdiri atas salinan buku tanah dan surat ukur. Dari hasil kegiatan dapat diperoleh data bahwa masyarakat kecamatan Sidamanik belum memahami pentingnya pendaftaran tanah, masyarakat merasa aman saja dengan sikon selama ini, karena kurangnya sosialisasi yang diberikan kepada masyarakat, sementara kebijakan pemerintah presiden Jokowi tahun 2018 sudah mengeluarkan Peraturan Menteri Agraria dan Tata Ruang/Kepala BPN Nomor 6 Tahun 2018 Tentang Pendaftaran Sistematis Lengkap (PTSL) program percepatan pendaftaran tanah bagi masyarakat.
\end{abstract}

Kata Kunci: Pentingnya; Pendaftaran; Tanah

\begin{abstract}
The importance of land registration is carried out in the Patronage Village of Pematang Siantar Subdistrict, Simalungan Regency for 2 days, August 14, 15, 2019. Conducted in the form of legal counselling in the field of Land Law, aims to provide knowledge and awareness to the community about the importance of land acquisition for the community to obtain certainty in the land to obtain certainty. The law for the land that is owned to create a sense of security for the people who own land that is claimed. Furthermore, there is legal protection to prevent interference and control of fellow citizens. With evidence produced at the end of the land registration process in the form of land books and land certificates consisting of copies of land books and measuring letters. From the results of the activity, it can be obtained data that the Sidamanik sub-district community does not understand the importance of land registration, the community feels safe with the situation so far, due to the lack of socialization given to the community, while the government policy of President Jokowi in 2018 has issued Minister of Agrarian and Spatial/Head Regulation BPN Number 6 of 2018 concerning Complete Systematic Registration program for accelerating land registration for the community.
\end{abstract}

Keywords: Importance; Registration; Soil 
Volume 2, Nomor 1, Tahun 2020 Hal 312 - 320

\section{PENDAHULUAN}

Simalungun Sumatera Utara, merupakan desa binaan dari Fakultas Hukum Universitas Kristen Indonesia yang telah beberapa kali dilaksanakan kegiatan Pengabdian pada masyarakat di desa tersebut. Masyarakat sebagian besar bekerja di sektor perusahaan perkebunan. Selain itu masyarakat di desa tersebut memiliki tanah namum dalam implementasinya masih banyak masyarakat kurang memahami Pentingnya Pendaftaran Tanah, masyarakat merasa aman saja dengan situasi kondisi yang ada saat ini. Namun ketika melakukan perbuatan hukum dalam bentuk jual beli, hibah, dan sebagainya atau peristiwa hukum dalam bentuk warisan menimbulkan persoalan dikemudian hari.

Untuk itu dalam rangka mewujudkan jaminan kepastian hak dibidang pertanahan ada dua hal yang harus diperhatikan, yaitu perlu adanya hukum tanah tertulis dan penyelenggaraan pendaftaran tanah. Dengan kata lain membicarakan pendaftaran tanah, berarti berbicara tentang salah satu usaha dalam rangka mewujudkan jaminan kepastian hukum dibidang pertanahan. Dengan demikian ada jaminan kepastian hukum dapat menimbulkan rasa mantap dan ras aman.

Makna dari rasa aman ini menunjukkan berupa tertulis sederhana mudah dimengerti oleh siapa saja dan konsisten dalam penerapannya. Sedangkan rasa aman ada kepastian tentang tanah yang dimiliki meliputi status tanah, siapa yang punya tanah tersebut dan pihak ketiga yang membebani serta perbuatan dan peristiwa hukum menyangkut penguasaan tanah, inilah pentingnya pendaftaran tanah.

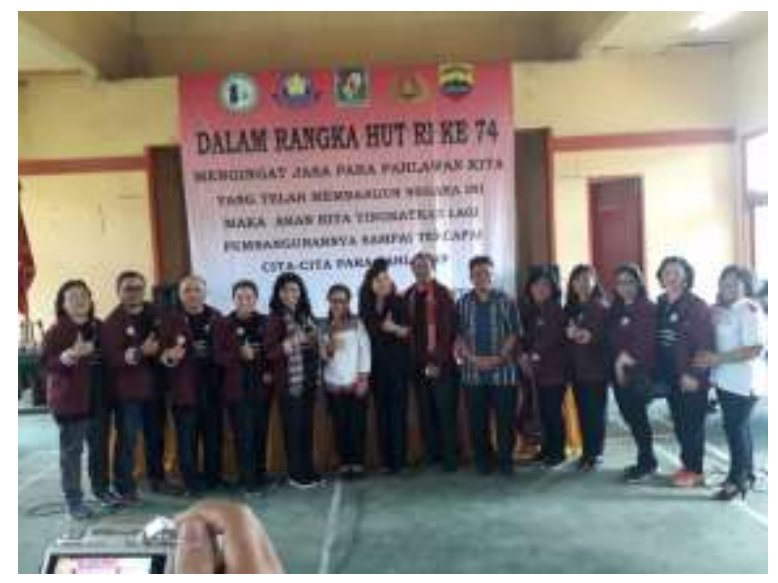

Gambar 1. Foto bersama Narasumber dan Peserta

Makna dari pentingnya pendaftaran tanah menunjukkan bahwa ada jaminan kepastian hukum dan kepastian hak atas tanah. Lalu kemudian pertanyaannya adalah kepetingan siapa saja yang dilindungi?. Respons atas 
Volume 2, Nomor 1, Tahun 2020 Hal 312 - 320

pertanyaan tersebut tergantung kepada kepentingan siapa saja terhadap hak atas tanah tersebut, antara lain sesuai dengan Pengabdian pada Masyarakat di Kecamatan Pematang Sidamanik, Kabupaten Simalungun makan kepentingan pemengang hak atas tanah dalam hal ini masyarakat agar dapat denga mudah membuktikan bahwa dialah yang berhak atas tanah yang bersangkutan. Caranya: dengan pendaftaran tanah maka akan diterbitkan surat tanda bukti hak berupa sertifikat. Berikutnya kepentingan pihak lain atau calon pembeli, calon kreditur agar mereka dapat dengan mudah memperoleh data yang dapat dipercayai kebenarannya. Caranya : karena administrasi dikantor pertanahan terbuka untuk umum, jadi siapapun yang berkepentingan bisa minta Surat Keterangan Pendaftran Tanah (SKPT).

Dengan dilakukan pendaftaran tanah maka masyarakat dapat mengetahui bahwa pendaftran tanah tersebut berfungsi untuk memperluas pembuktian dan memperkuat pembuktian. Hal ini dilakukan apabila dalam rangka jual beli dan pemindahan hak lainnya. Sedangkan dalam rangka permohonan hak yaitu sebagai syarat konstitusi atau syarat yang harus dipenuhi untuk lahirnya suatu hak dan untuk keperluan pembuktian.

Dengan kurangnya masyarakat mengetahui dan memahami pentingnya pendaftaran tanah mengakibatkan berbagai issue masalah hak atas tanah yang mungkin saja dialami oleh masyarakat di kemudian hari antara lain: timbulnya berbagai konflik, ketimpangan struktur penguasaan atau pemilikan tabah dan lemahnya jaminan Hukum atas pemilikan penguasaan dan penggunaan tanah. Ini akhirnya apabila tidak ditangani dengan cepat dapat mengakibatkan sengketa menyangkut tanah perkebunan, batas yang tumpang tindih, tukur menukar tanah, perampasan tanah masyarakat dalam konflik atau sengketa - sengketa dan sebangainya.

Merujuk pada hal - hal diatas maka pentingnya pendaftaran tanah yang yang memberi makna bahwa merupakan rangkain kegiatan yang dilakukan oleh pemerintah secara terus menerus, berkesinambungan dan teratur meliputi pengumpulan, pengolahan, pembukuan, dan penyajian serta pemeliharaan data fisik dan data 
Volume 2, Nomor 1, Tahun 2020 Hal 312 - 320

dalam bentuk peta dan daftar mengenai bidang - bidang tanah.

Dengan dikeluarkannya Program Pendaftaran Tanah Sistematis Lengkap (PTSL) yang merupakan program percepatan pendaftaran tanah, yang dilakukan pemerintah guna memberikan kepastian hukum hak atas tanah milik masyarakat secara menyeluruh. Manfaat PTSL ini mengurangi kasus sengketa dan konflik pertanahan.

Berkaitan dengan persoalan banyaknya tanak - tanak milik masyarakat di Kecamatan Pematang Sidamanik, Kabupaten Simalungun, Sumatera Utara yang belum didaftarkan maka perkumpulan pemuda Sidamanik Se-Indonesia melakukan permohonan dan permintaan untuk memberikan penyuluhan pada masyarakat yang ada di sekitar lokasi tersebut agar masyarakat memperoleh informasi dan semakin sadar dan peduli akan kepentingan hak atas tanahnya, Sehingga tidak terjadi sengketa atau konflik hak atas tanahnya. Dengan pertimbangan bahwa permasalahan tersebut harus segera diselesaikan, maka perkumpulan Pemuda Sidamanik melalui penghubung yaitu Ketuanya, bersama camat pematang sidamanik meminta kerjasama dengan Fakultas Hukum Universitas Kristen Indonesia dalam hal penanganan permasalahan pentingnya pendaftaran tanah di Kecamatan Pematang Sidamanik, Kabupaten Simalungun, Sumatera Utara. Pengajuan tersebut dibuktikan dengan adanya surat permintaan dari Perkumpulan Pemudan Sidamanik SeIndonesia dengan Camat Pematang Sidamanik.

Universitas Kristen Indonesia yang merupakan perguruan tinggi menjalankan kewajiban Tri Dharma perguruab Tinggi (salah satunya pengabdian kepada masyarakat, melalui Fakultas Hukum Menyambut baik permintaan dari Perkumpulan Pemuda Sidamanik Se-Indonesia). Camat pematang Sidamanik yang peduli terhadap kepentingan masyarakat akan status tanaknya agar mempunyai legalitas kepemilikan tanahnya, maka dengan mengirimkan Tim yang berkompeten dibidang pendaftaran tanah ke Desa Binaan Kecamatan Pematang Sidamanik, Kabupaten Simalungun. 
Volume 2, Nomor 1, Tahun 2020 Hal 312 - 320

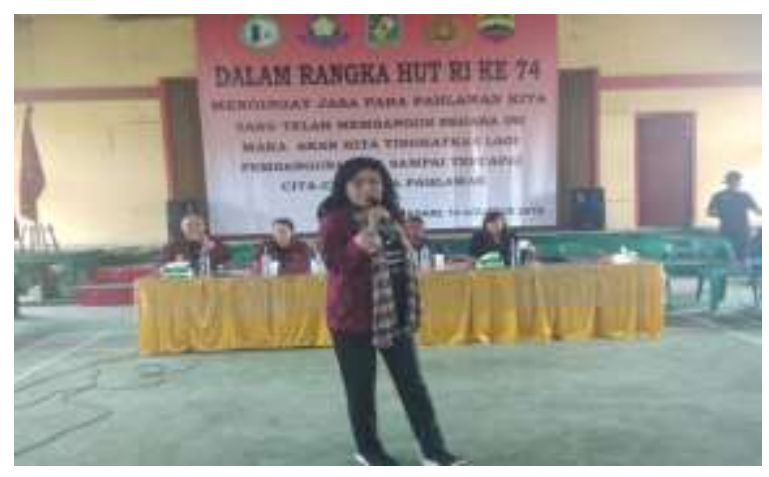

Gambar 2. Narasumber pada Saat Pemaparan

Dari hasil analisis kebutuhan sesuai dengan permintaan Perkumpulan Pemuda Sidamanik Se-Indonesia, Camat Pematang Sidamanik, maka yang menjadi prioritas kegiatan pengabdian pada masyarakat ini adalah melakukan penyuluhan, Advokasi seputar pertanahan tanah, problematika dan solusinya bagi masyarakat yang dilaksanakan di Balai Desa Kecamatan Pematang Sidamanik Sumatera Utara yang dihadiri sekitar 300 orang dari Kecamatan Pematang Sidamanik.

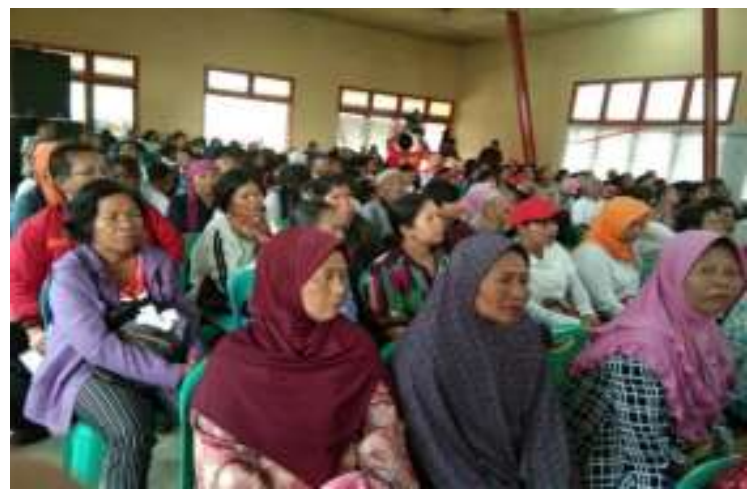

Gambar 3. Foto para Peserta Mengikuti Sesi dengan Serius

\section{Tujuan dan Manfaat}

Yang menjadi tujuan dari kegiatan Pengabdian pada masyarakat ini adalah:

1. Meningkatkan pengetahuan memahami dan mengetahui pentingnya pendaftran tanah.

2. Meningkatkan pengetahuan memahami dan mengetahui manfaat dan fungsi pendaftaran tanah.

3. Diharapkan program peduli masyarakat yang digagas oleh Perkumpulan Pemuda Sidamanik Se-Indonesia melalui penyuluhan pendaftaran tanah dapat terlaksana dengan baik.

\section{Manfaat}

Masyarakat di Desa Kecamatan Pematang Sidamanik dapat melaksanakan, melakukan pendataan tanah di Kabupaten Simalungun.

\section{METODE}

Metode yang digunakan dalam kegiatan pengabdian masyarakat ini dengan metode; metode penyampaian. Dalam penyuluhan hukum ini di sesuaikan dengan materi dan tempat penyuluhan, latar belakang peserta 
Volume 2, Nomor 1, Tahun 2020 Hal 312 - 320

penyuluhan yang dilakukan dengan cara sebagai berikut:

a. Ceramah

Metode ceramah di gunakan untuk menyampaikan materi penyuluhan, yang meliputi dasar hukum, Peraturan Perundang Undangan di bidang Hukum Pertanahan, kebijakan pemerintah yang mendasari kepemilikan atas tanah. Dengan metode ini dapat menjangkau seluruh peserta kegiatan secara merata dan penyampaian materi dapat di lakukan secara sistimatis.

b. Diskusi Interaktif atau Tanya Jawab. Metode ini di gunakan untuk mengetahui seberapa jauh masyarakat memahami terhadap materi ceramah yang disampaikan serta untuk menggali lebih dalam permasalahan yang dihadapi masyarakat khususnya pada pendaftaran tanah.

C. Konsultasi

Metode ini sangat efektif di gunakan untuk membantu para peserta yang tidak berani mengemukakan

permasalahannya/bertanya dimuka umum, sehingga tim fasilitator dapat mengelaborasikan lebih dalam problematika atau kesulitan yang dialami oleh peserta penyuluhan atau warga masyarakat. Dengan demikian dapat diperoleh informasi yang valid pada peserta penyuluhan (masyarakat).

d. Metode Evaluasi.

Dalam metode ini, kegiatan yang dilakukan adalah pembagian kuesioner yang di isi oleh responden. Dengan demikia dapat memperoleh informasi secara detail, mendalam dan akurat, yang kemudian akan dianalisis dan memperoleh kesimpulan.

\section{HASIL DAN PEMBAHASAN}

Berdasarkan hasil dari kegiatan Pengabdian kepada masyarakat yang telah di laksanakan dalam bentuk penyuluhan hukum di bidang pertanahan dengan judul Tata cara pendaftaran tanah dan Penyelesaian 
Volume 2, Nomor 1, Tahun 2020 Hal 312 - 320

sengketa tanah, maka hasil yang di capai adalh sebagai berikut:

1. Tercapainya Tujuan.

Sebagaimana telah di uraikan pada permasalahan sebelumnya maka tujuan tersebut telah tercapai dengan baik yaitu:

\section{a. Peserta Penyuluhan} memahami atau mengetahui hukum pertanahan yang mengatur perlindungan terhadap hak atas tanah.

b. Peserta penyuluhan memahami mengenai syarat syarat dan prosedur memperoleh bukti kepemilikan atas tanah.

2. Tercapainya Target.

Target telah dapat dicapai, yaitu dalam kegiatan penyuluhan hukum ini di hadiri ole sekitar 300 orang peserta yang meliputi warga desa kecamatan pematang sidamanik jajaran aparat desa dll telah mendapat pengetahuan yang baru dibidang hukum pertanahan khususnya tata cara pendaftaran tanah,sehingga meningkatkan pemahaman peserta tentang tanda bukti hak atas tanah (sertifikat).
Berdasarkan data kuesioner yang berhasil di kumpulkan maka dapat di simpulkan bahwa masyarakat kecamatan pematang sidamanik pada umumnya tidak mau mendaftarkan tanahnya oleh karena selama ini mereka aman aman saja dan tidak ada sanksi dari pemerintah apabila mereka tidak mendaftarkan tanahnya.

Lebih dari pada itu kabupaten cukup jauh jaraknya dari kecamatan pematang sidamanik apabila mereka hendak mendaftarkan tanahnya, disamping juga adanya kekhawatiran biaya pendaftaran yang mahal.

Ketentuan Peraturan Pemerintah tentang pendaftaran tanah(PP 24 Tahun 1997) yang merupakan pelaksanaan dari UUPA (Undang Undang no 5 tahun 1960) yang menentukan bahwa untuk menjamin kepastian hukum maka hak atas tanah harus di daftarkan.pasai 1 angka 1 PP 24 Tahun 1997 menyebutkan tentang pengertian pendaftaran tanah adalah rangkaian kegiatan yang dilakukan oleh pemerintah secara terus menerus,berkesinambungan,dan teratur,meliputi pengumpulan,pengolahan, pembukuan dan penyajian serta pemeliharaan data 
Volume 2, Nomor 1, Tahun 2020 Hal 312 - 320

fisik dan data yuridis dalam bentuk peta dan daftar mengenai bidang bidang tanah dan satuan satuan rumah susun ,termasuk pemberian surat tanda bukti haknya bagi bidang bidang tanah yang sudah ada haknya dan hak milik atas satuan rumah susun serta hak hak tertentu yang membebaninya.

Berdasarkan pengertian tersebut di atas maka jika mayarakat sidamanik memahami tentang pentingnya pendaftaran tanah maka seharusnya tidak perlu ada kekhawatiran untuk mendaftarkan tanahnya karea dengan demikian akan tercapai kepastian hukum di bidang pertanahan dengan di terbitkannya sertifikat.

Sementara diatur dalam Permen ATR/KBPN Nomor 6 Tahun 2018 Pendaftaran Tanah Sistematis Lengkap (PTSL) merupakan kegiatan pendaftaran tanah untuk pertama kali yang dilakukan secara serentak bagi semua objek pendaftaran tanah di seluruh wilayah Republik Indonesia dalam satu wilayah desa/kelurahan atau nama lainnya yang setingkat dengan itu, yang meliputi pengumlan data fisik dan data yuridis mengenai satu atau beberapa objek pendafataran tanh untuk keperluan pendaftarannya.
Objek PTSL meliputi seleruh bidang tanah yang belum ada hak atas tanahnya maupun bidang tanah hak yang memiliki hak dalam rangka memperbaiki kualiatas data pendaftran tanah berupa: Tanah yang sudah terdaftar (bersertifikat); Tanah yang belum terdaftar (Tanah sudah ada hak dan tanah belum ada hak (Tanah negara bebas dan tanah negara bebas hak).

PTSL adalah program percepatan pandaftaran tanah, yang dilakukan pemerintah guna memberikan kepastian hukum hak atas tanah milik masyarakat. Sangat diperlukan oleh masyarakat secara menyeluruh.

Terbitnya sertifikat hak atas tanah guna kepastian dan perlindungan hukum kepada subjek pajak. Untuk mengurangi kasus sengketa dan konflik pertanahan maka sertifikat dapat menjadi collateral di Bank untuk usaha produktif, menuju kesejahteraan pemilik tanah.

\section{KESIMPULAN}

Penyuluhan hukum tentang pentingnya pendaftaran tanah desa Binaan, Kecamatan Pematang Sidamanik, Kabupaten Simalungun, Sumatera Utara sangat efektif dilakukan 
Volume 2, Nomor 1, Tahun 2020 Hal 312 - 320

mengingat warga masyarakat kurang menerima informasi dan sosialisasi tentang pentingnya pendaftaran tanah dan tata cara pendaftaran tanah. Disamping itu mereka merasa nyaman saja dengan keadaan mereka selama ini, tidak ada sanksi dari pemerintah untuk mendaftarkan tanahnya. Dengan adanya penyuluhan pentingnya pendaftaran tanah masyarakat menjadi memahami arti pentingnya pendaftaran bagi masyarakat untuk kepastian hukum dan kepastian hak atas tanahnya

\section{UCAPAN TERIMA KASIH}

Ucapan terima kasih kami sampaikan kepada:

1. Fakultas Hukum Universitas Kristen Indonesia sebangai pelaksana

2. Seluruh rekan - rekan dosen Fakultas Hukum Universitas Kristen Indonesia

3. Pemuda Kecamatan Pematang Sidamanik, Kabupaten Simalungun 4. Pemda Kecamatan Pematang Sidamanik, Kabupaten Simalungun, Sumatera Utara

\section{REFERENSI}

Boedi, H. (2005). 2008. Hukum Agraria Indonesia, Sejarah Pembentukkan UUPA, Isi \& Pelaksanaannya.

Tehupeiory, A. (2012). Pentingnya pendaftaran tanah di Indonesia. RAIH ASA SUKSES.

Soemitro, R. H. (1990). Metodologi penelitian hukum dan jurimetri. Ghalia Indonesia, Jakarta, 167.

Hermit, H. (2004). Cara memperoleh sertifikat tanah hak milik, tanah negara, dan tanah pemda: teori dan praktek pendaftaran tanah di Indonesia. Mandar Maju.

Direktorat Jenderal Penanganan Masalah Agraria Pemanfaatan Ruang dan Tanah (2019). Peluang dalam Pemanfaatan Program Percepatan Pendaftaran Tanah melalui PTSL, Jakarta 